\title{
Toxicity Evaluation of Chlorpyrifos Metabolite 3,5,6- trichloro-2-pyridinol to Eisenia fetida in Different Soils
}

\section{Kaixuan Hou}

Shandong Agricultural University

\section{Yue Yang}

Shandong Agricultural University

Lei Zhu

Shandong Agricultural University

Ruolin Wu

Shandong Agricultural University

Albert Juhasz

University of South Australia

Jun Wang

Shandong Agricultural University

Jinhua Wang

Shandong Agricultural University

Zhongkun Du

Shandong Agricultural University

Bing Li

Shandong Agricultural University

Lusheng Zhu ( $\square$ lushzhu@sdau.edu.cn )

Shandong Agricultural University https://orcid.org/0000-0001-6212-1965

\section{Research Article}

Keywords: Earthworms, Artificial soil, Fluvo-aquic soil, Black soil, Red clay, Oxidative stress, Integrated Biomarker Response (IBR)

Posted Date: June 21st, 2021

DOI: https://doi.org/10.21203/rs.3.rs-529333/v1

License: (a) (i) This work is licensed under a Creative Commons Attribution 4.0 International License. Read Full License 


\section{Abstract}

The present study utilized a biomarker response method to evaluate the effect of 3,5,6-trichloro-2pyridinol (TCP) in artificial and natural soils on Eisenia fetida after 7, 14, 28, 42 and 56 days exposure. Biomarker responses were standardized to calculate the Integrated Biomarker Response (IBR) index. The influence of soil type on TCP toxicity was assessed. Results indicated that TCP induced excessive reactive oxygen species, caused oxidative stress, DNA damage to earthworm, which is similar to its parent chemical chlorpyrifos. The IBR index of three enzymes activities showed that TCP induced the enzymes activities of earthworm in red clay was stronger than the other three soils. Specifically, chlorpyrifos exposure group showed a lower toxicity than TCP exposure group after 28 days exposure but a higher toxicity than TCP exposure group after 56 days exposure. Despite the deficiencies of this study, the above information is of great significance for assessing the risk of chlorpyrifos and its metabolite TCP pollution in soil ecosystems.

\section{Introduction}

The extensive use of pesticides has brought great dividends to agricultural production, but also inevitably caused harm to non-target organisms. Chlorpyrifos, an organophosphate insecticide (Jhon and Shaike. 2015), was widely used during the past half century for pest control. However, chlorpyrifos was highly toxic to non-target organisms. The acute oral $\mathrm{EC}_{50}$ for rat and bird were 66 and $39.2 \mathrm{mg} / \mathrm{kg}$, respectively. Chlorpyrifos is toxic to soil microorganisms (Dutta et al., 2010; Orts et al., 2017), plants (Bassey et al., 2015), aquatic system (Ali et al., 2009; Costa et al., 2015; Bonifacio et al., 2017) and even to the higher vertebrates (Sandal and Yilmaz, 2011; Wang et al., 2012; Ojha et al., 2013). Recently, García-Gómez et al. (2019) using earthworms (Eisenia andrei) demonstrated that chlorpyrifos exposure (40 $\mathrm{mg} / \mathrm{kg}$ ) reduces acetylcholinesterase (AChE) activity and impacts male reproductive abilities. Our previous study (Zhu et al., 2020) using a biomarkers response method demonstrated that chlorpyrifos caused oxidative and DNA damage to Eisenia fetida. The toxicological response varied depending on physicochemical properties. In red clay, the clay content affects the toxicity of chlorpyrifos to earthworms. In summary, previous studies have detailed the behavioral, neurological and reproductive effects on organisms thus providing a good knowledge regarding the chlorpyrifos' environmental impact.

However, soil impact may be caused by both the parent compound and the metabolites, therefore, the toxicity of metabolites should also be considered when assessing ecological impact. 3,5,6-trichloro-2pyridinol (TCP) is the primary metabolite of chlorpyrifos (Žabar et al., 2016; Wang et al., 2019). TCP has a half-life in the soil of up to 360 days and an aqueous solubility of $80.9 \mathrm{mg} / \mathrm{L}$, indicating its longer persistence in the environment and potential mobility (Deng et al., 2016). Research on TCP has focused on degradation or biodegradation (Bempelou et al., 2018; Yu et al., 2019; Zhang et al., 2019) as well as aquatic toxicity (Wang et al., 2014; Suvarchala and Philip, 2016; Echeverri-Jaramillo et al., 2020) and mice toxicity (Deng et al., 2016). Earthworms contributed greatly to soil improvement (Blakemore and Hochkirch, 2017). Eisenia fetida was recommended as a model soil organism in soil for toxicological assessment (OECD 222, 2016; Wen et al., 2020). However, to our best knowledge, there are no published 
literature on the effect of TCP on earthworms and particularly Eisenia fetida. Whether adverse effects can be induced by TCP to Eisenia fetida should be studied.

In this study, the effects on Eisenia fetida of TCP exposure were assessed by monitoring the response of biomarkers including reactive oxygen species (ROS), enzyme activities of superoxide dismutase (SOD), catalase (CAT), as well as glutathione S-transferase (GST), lipid peroxidation (MDA content), and 8hydroxydeoxyguanosine (8-OHdG). Artificial soil and three different natural soils were selected to assess the soil type effects on TCP toxicological response. The Integrated Biomarker Response (IBR) index (Samanta et al., 2018; Sanchez-Hernandez et al., 2019) was calculated to compare the effect of TCP exposure in different soils to earthworms and to compare the effect of TCP exposure with chlorpyrifos.

It was hypothesized that TCP was more toxic in red clay with high clay content and the toxicity of the metabolite TCP was greater than the parent compound chlorpyrifos.

\section{Materials And Methods}

\subsection{Chemical and reagents}

TCP (CAS 6515-38-4; 99.0\% purity) was purchased from AccuStandard Co., Ltd. (New Haven, USA). The ELISA kit used to assess the 8-OHdG content was purchased from Hengyuan biological technology Co. Ltd. (Shanghai, China). Chromatographical grade acetonitrile was purchased from Tedia Co., Inc. (Ohio, USA). The other reagents involved in this study are all of analytical purity.

\subsection{Soil, earthworms and experiment design}

Soils involved in this study were in keep with our previously chlorpyrifos study. According to the Organization for Economic Co-operation and Development guideline (OECD 222, 2016), artificial soil consists of 10 per cent sphagnum peat, 20 per cent kaolin clay, 70 per cent air-dried quartz sand and a small amount of calcium carbonate for pH regulation (Zhang et al., 2018; Liu et al., 2020a). The fluvoaquic soil was sampled from Dezhou, Shandong, China $\left(36.78^{\circ} \mathrm{N}, 116.54^{\circ} \mathrm{E}\right)$. The black soil was sampled from Changchun, Jilin, China $\left(43.80^{\circ} \mathrm{N}, 125.40^{\circ} \mathrm{E}\right)$. The red clay was sampled from Nanning, Guangxi, China $\left(22.74^{\circ} \mathrm{N}, 109.31^{\circ} \mathrm{E}\right)$, respectively. Properties of three soils are shown in Table $\mathrm{S} 1$.

Adult Eisenia fetida were acquired from an earthworm farm (Shandong, China). Healthy, mature earthworms with weight 300 to $500 \mathrm{mg}$ and possessed visible clitellum were randomly selected for biomarkers assessment (OECD 222, 2016).

As previously studied, the concentration of chlorpyrifos was set as $0.01,0.1$, and $1 \mathrm{mg} / \mathrm{kg}$. To facilitate the comparison of toxicity of chlorpyrifos and TCP. Several TCP-acetonitrile solutions with different concentrations were used to contaminate $500 \mathrm{~g}$ soil with final concentrations of TCP in soil to be 0.01 , $0.1,0.5 \mathrm{mg} / \mathrm{kg}$ dry soil. A solvent control group $(0 \mathrm{mg} / \mathrm{kg})$ was included where only acetonitrile was added to the soil. Contaminated soil was fully mixed and adjusted moisture after acetonitrile had volatilized in the fume hood until completely dry. The prepared soil was then transferred to $1 \mathrm{~L}$ glass 
breakers and twenty earthworms were then cultured with each soil/TCP concentration assessed using three replicates. Assays were conducted at $20^{\circ} \mathrm{C}, 80 \%$ humidity and a light-dark cycle of 16 hours light and 8 hours dark with illumination of 650 lux according to OECD 222, 2016 (Song, et al. 2019).

\subsection{Sample preparation and biomarkers responses assessment}

On day 7, 14, 21, 28 and 56, earthworms were sampled to assess biomarker response. To assess ROS, intestinal emptied earthworms were ice-bath homogenized (Jingxin, F6/10, China) at high speed with phosphate buffer saline (PBS) and centrifuged (Eppendorf, Centrifuge $5810 \mathrm{R}$, Germany) at $3000 \mathrm{~g}\left(4^{\circ} \mathrm{C}\right)$ for $10 \mathrm{~min}$. The supernatant was collected then centrifuged at $20000 \mathrm{~g}\left(4^{\circ} \mathrm{C}\right)$ for $20 \mathrm{~min}$ after which the precipitate was resuspended in $1 \mathrm{~mL}$ PBS. To assess SOD, CAT, GST activity and MDA content, intestinal emptied earthworms were ice-bath homogenized at high speed with PBS and centrifuged at $10000 \mathrm{rpm}$ $\left(4^{\circ} \mathrm{C}\right)$ for $10 \mathrm{~min}$. According to Bradford (1976), protein content of the above two samples was determined by Coomassie. To assess $8-\mathrm{OHdG}$ content, intestinal emptied earthworms were ice-bath homogenized at high speed with PBS and centrifuged at $6500 \mathrm{rpm}\left(4^{\circ} \mathrm{C}\right)$ for $15 \mathrm{~min}$.

All biomarker assessment methods were in keeping with our previous study (Zhu et, al. 2020), the details of methods are shown in Table S2.

\subsection{Statistical analyses}

The Statistical Package for Social Sciences (SPSS, V22.0) was used to analyze data and Origin (OriginPro, 2021, SR1) was used to plot. One-way analysis of variance (ANOVA) was used to analyze the least significance differences $(p<0.05)$ between the control treatment and each TCP exposure group.

Data from this study (TCP exposure) and our previous study (chlorpyrifos exposure) (Zhu et, al. 2020) were used to calculate the IBR index. How the biomarker data was used to calculate IBR was detailed in supplementary material according to Sanchez et, al (2013).

\section{Results And Discussion}

\subsection{Effects of TCP on Eisenia fetida: biomarkers responses 3.1.1 Oxidative stress: ROS content and enzyme activities}

Reactive oxygen species (ROS) are highly reactive chemical species formed due to the electron acceptability of oxygen. Excessive ROS has a destructive effect and promotes oxidative stress (Li et al., 2019). Over a 56-day period, the variation of ROS level was assessed following exposure to TCP (Fig. 1).

In all four soils, the ROS significantly increased in the TCP exposed group in different soils during the experimental period. In the OECD artificial soil and black soil, a dose-response relationship was observed whereby increasing ROS content was observed with increasing TCP concentration. In fluvo-aquic soil, a 
similar dose-response relationship was observed except at day 56 where ROS content of $0.5 \mathrm{mg} / \mathrm{kg}$ dose group decreased compared to $0.1 \mathrm{mg} / \mathrm{kg}$ dose group. In red clay, no significant difference in ROS response was observed between 0.01 and $0.1 \mathrm{mg} / \mathrm{kg}$ dose groups at day $7,14,42$ and 56 as well as 0.1 and $0.5 \mathrm{mg} / \mathrm{kg}$ dose groups on day 28 .

In the present study, the result indicates that TCP exposure induces excessive ROS production in Eisenia fetida and, in most cases, a dose-response relationship was observed. A similar result was observed in our previous study (Zhu et al., 2020) where TCP's parent chlorpyrifos exposure resulted in excessive ROS production in earthworms in the same four soils. Excessive ROS production in Eisenia fetida after exposure to TCP and its parent chorpyrifos indicates that they caused oxidative stress to Eisenia fetida. From the point of inducing excessive ROS, the toxicity of TCP and chlorpyrifos was similar.

In order to mitigate oxidative stress caused by excessive ROS, Eisenia fetida could produce a battery of enzymes like SOD, CAT and GST. SOD and CAT, the first defense line of cellular protection (Wang et al., 2018), are produced by organisms to inactivate ROS preventing oxidative stress and consequent damage. SOD could transform $\mathrm{O}_{2}{ }^{-}$into $\mathrm{H}_{2} \mathrm{O}_{2}$, which could be detoxified by CAT (Liu et al., 2020b). These two enzymes (SOD and CAT) constitute the antioxidant enzyme system to jointly combat oxidative stress. GST contributes greatly to oxidation protection and xenobiotic metabolism, as it also detoxifies ROS in cells. (Zhu et al., 2011).

The detailed changes in SOD, CAT, GST enzyme activities are illustrated in Fig. S1-S3. Unlike with ROS content, the dose-response was not observed for the biomarkers SOD, CAT, and GST with some values higher than the control group following TCP exposure and some lower than the control group. The SOD activity was significantly activated in the early stage of exposure and gradually decreased to the control level in the later stage in all four soils. The CAT and GST activity was activated in most periods.

To clearly evaluate Eisenia fetida oxidative stress in different soils caused by TCP exposure, the IBR index calculated using SOD, CAT and GST (IBR index of SCG) activity was used to describe an integrate biomarkers responses. The IBR index could indicate the toxicity of pollutants and able to assess environmental pollution risk (Wang et al., 2011; Shao et al., 2019). The normalized calculated IBR index of SCG is illustrated in Fig. 2.

The variation of Eisenia fetida enzyme activities including SOD, CAT, and GST shows the early oxidative damage caused by TCP. The oxidative damages suffered by earthworms in 4 soils are different. During the experimental period, the IBR index of SCG in red clay were higer than that in the other three soils. On day 7 and 14, the IBR index of SCG in black soil was little higher than that in fluvo aquic soil and much higher than that in artificial soil. On day 28,42 and 56 , the IBR index of SCG in fluvo-aquic soil was much higher than that in artificial and black soil.

Organic matter (Gebremariam et al., 2012), pH, cation exchange capacity and clay content could interact with chemical substances (Stepnowski et al., 2007). The IBR index of SCG indicates that oxidative stress caused by TCP in red clay and fluvo-aquic soil was higher than that in artificial and black soil. This may 
due to that the organic carbon of red clay and fluvo-aquic soil is lower than that of artificial soil and black soil. Zhu et al. (2020) demonstrated that chlorpyrifos was more toxic to Eisenia Fetida in red clay with high clay content (71.3\%). Xu et al. (2021) stated that azoxystrobin had more lasting adverse effects on earthworms in soils with low organic matter content and low $\mathrm{pH}$. These results are consistent with that in the present study, TCP also has a greater influence on SCG in red clay than in the other three soils. In general, the higher toxicity of TCP in red clay than the other three soils may be due to the fact that red clay has lower organic matter and $\mathrm{pH}$, and higher clay content $(71.3 \%)$ than the other three soils.

\subsubsection{Lipid peroxidation: MDA contents}

Excessive ROS can cause lipid peroxidation (LPO), which damages cell membranes and causes cell damage. MDA content could reflect the degree of LPO (Box and Maccubbin, 1997). Figure 3 illustrates the changes in Eisenia fetida MDA content influenced by TCP in soils.

In artificial soil, the MDA contents of each concentration exposure group were significantly higher than that of control group except for 7th, 42nd day $0.01 \mathrm{mg} / \mathrm{kg}$ group. In fluvo-aquic soil, the same trend was observed but no significant discrepancy was observed between 7th, 14th day $0.01 \mathrm{mg} / \mathrm{kg}$ group and control group. In black soil, the MDA contents at diverse concentration were significantly higher than that of the control group except for 7th day $0.01 \mathrm{mg} / \mathrm{kg}$ group. In red clay, on day 7 and 28 , the MDA contents of medium and high concentration $(0.1 \mathrm{and} 0.5 \mathrm{mg} / \mathrm{kg})$ group were significantly higher than that of control group but no significant discrepancy was observed between low concentration $(0.01 \mathrm{mg} / \mathrm{kg})$ and control group. On day 14 , only the MDA contents of high concentration $(0.5 \mathrm{mg} / \mathrm{kg})$ group were significantly higher than that of control group. On day 42 and 56 , the MDA contents of each concentration group were significantly higher than that of the control group.

As we previously studied (Zhu et, al., 2020), TCP's parent chlorpyrifos exposure significantly increased the MDA content in Eisenia fetida over a 4 weeks exposure. Li et al. (2019) demonstrated that another organophosphorus insecticide tolclofos-methyl could also significantly incresed the MDA content in Eisenia fetida. Uniformly, the MDA content in Eisenia fetida was significantly increased after exposed to TCP and the increase was more obvious in the later stage of the experiment. This indicated that TCP exposure caused lipid peroxidation to Eisenia fetida.

\subsubsection{DNA oxidative damage: 8-OHdG contents}

The product generated when ROS attacking DNA (Guo et al., 2014), 8-hydroxy-2-deoxyguanosine (8$\mathrm{OHdG}$ ) could indicate the degree of oxidative and DNA damage (Zhang et al., 2014). Figure 4 illustrates changes in 8-OHdG content in different soils after exposure to TCP.

In artificial soil, the 8-OHdG contents of each concentration group were significantly higher than that of control group. However, the significant difference between the 0.1 and $0.5 \mathrm{mg} / \mathrm{kg}$ exposure group was not observed on day 42 . Furthermore, on day 28 , the $8-0 H d G$ content in the $0.1 \mathrm{mg} / \mathrm{kg}$ exposure was significantly lower than that of 0.01 and $0.5 \mathrm{mg} / \mathrm{kg}$ exposure. In natural soils, the $8-\mathrm{OHdG}$ in TCP 
concentration groups were significantly higher than that of $0 \mathrm{mg} / \mathrm{kg}$. A dose-response relationship was observed.

The increase in 8-OHdG content indicates that TCP induced DNA damage to Eisenia fetida. As we previously studied (Zhu et, al., 2020), chlorpyrifos treatments also significantly increased the earthworm's 8-OHdG content. Zhang et al. (2014) also demonstrated that Dechlorane Plus could induce an increase of earthworm's 8-OHdG content. Besides, 1-methyl-3-(tetrahydro-3-furylmethyl) urea and 1-methyl-3(tetrahydro-3-furylmethyl) guanidium dihydrogen, which are two main metabolites of the insecticide dinotefuran, were stated that induced DNA damage in Eisenia fetida cells (Liu et al., 2018). Based on the response of 8-OHdG content to TCP exposure, TCP has a certain effect on DNA oxidative damage to Eisenia fetida in all four soils.

In summary, the result shows that TCP is a toxic pollutant to earthworms because TCP can induce excessive ROS, alter enzyme activity and induce lipid peroxidation as well as DNA damage. In addition, the effects on Eisenia fetida of TCP in red clay was higher than that in the other three soils, followed by fluvo-aquic soil and black soil, the lowest was artificial soil. This may due to the low organic matter content in red clay and fluvo-auic soil and the high clay content in red clay. We believe that artificial soil toxic experiment may not correctly evaluate the toxicity of TCP in natural soil including fluvo-aquic soil and red clay.

TCP has a similar effect on earthworms compared to the parent chemical chlorpyrifos. However, the toxicity of TCP and chlorpyrifos to earthworms may further be elucidated by calculating the IBR index.

\subsection{Toxicity comparison of TCP and chlorpyrifos: IBR index}

In the present study, IBR index of each exposure group was the sum of six biomarker responses (ROS, SOD, CAT, GST, MDA, 8-OHdG). Figure 5A illustrates the IBR index of chlorpyrifos (Zhu et, al., 2020) and TCP when Eisenia fetida was exposed to $0.1 \mathrm{mg} / \mathrm{kg}$ for 28 days and 56 days in different soils. Figure 5B illustrates the change in each biomarker over this time frame. Data on the effects of chlorpyrifos on earthworms (ROS, SOD, CAT, GST, MDA, 8-OHdG) were obtained from our previous study (Zhu et al., 2020).

As shown in Fig. 5A, on day 28, the IBR index of chlorpyrifos (Zhu et, al. 2020) and TCP toxicity to Eisenia fetida were 9.82 and 13.60, 10.23 and 18.62, 9.34 and 17.15, 12.21 and 14.88 in artificial, fluvo-aquic soil, black soil and red clay, respectively. On day 56, the IBR index of chlorpyrifos (Zhu et, al. 2020) and TCP toxicity to Eisenia fetida were 14.10 and $9.23,15.30$ and $14.50,13.20$ and $9.41,16.30$ and 7.83 in artificial, fluvo-aquic soil, black soil and red clay, respectively. In addition, as the hydrolysis metabolite compound of chlorpyrifos, TCP was more toxic than chlorpyrifos at the same dose $(0.1 \mathrm{mg} / \mathrm{kg})$ after 28 days exposure, which the toxicity of TCP was about 38, 82, 84 and 22 percent more than that of chlorpyrifos in artificial, fluvo-aquic soil, black soil and red clay, respectively. In contrast, TCP was less toxic than chlorpyrifos at the same dose $(0.1 \mathrm{mg} / \mathrm{kg})$ after 56 days exposure, which the toxicity of TCP was about 35, 5, 29 and 52 percent less than that of chlorpyrifos in artificial, fluvo-aquic soil, black soil 
and red clay, respectively. It is also worth mentioning that TCP was less toxic on day 56 than on day 28 , but chlorpyrifos was more toxic. Figure 5B illustrates the degree of contribution of biomarkers to IBR index. In artificial soil, 8-OHdG content contributed the most to the IBR index of chlorpyrifos and TCP to Eisenia fetida. In fluvo-aquic soil, SOD activity contributed the most to the IBR index of chlorpyrifos while 8-OHdG content contributed the most to the IBR index of TCP to Eisenia fetida. In black soil, 8-OHdG content contributed the most to the IBR index of chlorpyrifos while MDA content contributed the most to the IBR index of TCP to Eisenia fetida. In red clay, MDA content contributed the most to the IBR index to chlorpyrifos while CAT activity contributed the most to the IBR index of TCP to Eisenia fetida. In general, the production of lipid peroxidation MDA content and the production of DNA damage 8-OHdG content were most sensitive to TCP contamination.

There have also been several reports comparing the toxicity of chlorpyrifos with its metabolite TCP. For aquatic organisms, TCP was found to be more toxic than chlorpyrifos to Daphnia carinata survival in cladoceran water but less toxic in natural water (Cáceres et al., 2007). Echeverri-Jaramillo et al. (2020) found that TCP was more toxic than chlorpyrifos to Aliivibrio fischeri and Pseudokirchneriella subcapitata but less toxic than chlorpyrifos to Daphnia magna. This suggests that chlorpyrifos itself may be less toxic than TCP, but once degraded and converted to TCP or other transformation products, it becomes more toxic. Kharabsheh et al. (2017) demonstrated that the bacteria Pseudomonas aeruginosa metabolized chlorpyrifos to TCP increasing the mortality of adult zebrafish (Danio rerio). Besides, Li et al. (2020) demonstrated that TCP had a key role in chlorpyrifos-induced decrease in testosterone synthesis of mice. In combination with the present study, for terrestrial organisms especially earthworms (Eisenia fetida), TCP was more toxic than its parent chemical chlorpyrifos after 28 days exposure but less toxic after 56 days exposure.

\section{Conclusions}

In the present study, the chronic toxicity of TCP to Eisenia fetida was determined in artificial soil prepared according to the OECD and three natural soils (fluvo-aquic soil, black soil and red clay) by monitoring the change of biomarker responses (ROS, SOD, CAT, GST, MDA, 8-OHdG). The IBR index was calculated to compare the toxicity of TCP with chlorpyrifos to Eisenia fetida in different soils. The primary conclusions showed by the results are as follows:

(1) TCP caused oxidative stress and DNA damage to Eisenia fetida and artificial soil toxicity experiment may underestimate the TCP toxicity in natural soil.

(2) As the metabolite compound of chlorpyrifos, TCP was more toxic than chlorpyrifos after 28 days exposure but less toxic after 56 days at the same dose $(0.1 \mathrm{mg} / \mathrm{kg})$.

Based on previous studies, we speculate that this is due to chlorpyrifos metabolism to TCP and other metabolites after 56 days. Thus, an approach to monitor the concentration changes in chlorpyrifos and TCP should be established in future studies to demonstrating this. Despite the deficiencies of this study, 
the above information is of great significance for assessing the risk of chlorpyrifos and its metabolite TCP pollution in soil ecosystems.

\section{Declarations}

Ethics approval and consent to participate

Not applicable

Consent for publication

Not applicable

\section{Availability of data and materials}

The authors confirm that the data supporting the findings of this study are available within the article and supplement materials.

\section{Competing interests}

The authors declare that they have no competing interests

\section{Funding}

The present study was supported by the National Natural Science Foundation of China [grant numbers 42077042 and 41907357].

\section{Authors' contributions}

Kaixuan Hou: Conceptualization, Formal analysis, Investigation, Writing - original draft, review and editing.

Yue Yang: Validation, Formal analysis, Writing - review \& editing; Lei Zhu: Conceptualization, Investigation.

Ruolin Wu: Validation, Investigation; Albert Juhasz: Writing - review \& editing; Jun Wang: Writing - review \& editing; Jinhua Wang: Writing - review \& editing; Zhongkun Du: Writing - review \& editing; Bing Li: Writing - review \& editing; Lusheng Zhu: Conceptualization, Methodology, Investigation, Validation, Supervision, Funding acquisition, Project administration, Writing - review \& editing.

\section{Acknowledgements}

We are thankful to Jun Wang and Jinhua Wang for the Special Funds of Taishan Scholar of Shandong Province, China. 


\section{References}

1. Ali, D., Nagpure, N.S., Kumar, S., Kumar, R., Kushwaha, B. and Lakra, W.S., 2009. Assessment of genotoxic and mutagenic effects of chlorpyrifos in freshwater fish Channa punctatus (Bloch) using micronucleus assay and alkaline single-cell gel electrophoresis. Food and Chemical Toxicology 47(3), 650-656. https://doi.org/10.1016/j.fct.2008.12.021

2. Bassey, Y.I., Effiong E.B., Archibong, U.D., Ita, W.I., 2015. Germination and Root Nodule Formation of Soybean (Glycine max (L.) Merr.) in Ridomil and Chlorpyriphos Treated Soil. American Journal of Environmental Protection 4(1), 17-22. https://doi.org/10.11648/j.ajep.20150401.12

3. Bempelou, E.D., Vontas, J.G., Liapis, K.S., Ziogas, V.N., 2018. Biodegradation of chlorpyrifos and 3,5,6trichloro-2-pyridinol by the epiphytic yeasts Rhodotorula glutinis and Rhodotorula rubra. Ecotoxicology 27(10), 1368-1378. https://doi.org/10.1007/s10646-018-1992-7

4. Blakemore, R.J., Hochkirch, A., 2017. Restore earthworms to rebuild topsoil. Nature 545, 30. https://doi.org/10.1038/545030b

5. Bonifacio, A.F., Ballesteros, M.L., Bonansea, R.I., Filippi, I., Ame, M.V., Hued, A.C., 2017. Environmental relevant concentrations of a chlorpyrifos commercial formulation affect two neotropical fish species, Cheirodon interruptus and Cnesterodon decemmaculatus. Chemosphere 188, 486-493. https://doi.org/10.1016/j.chemosphere.2017.08.156

6. Box, H.C., Maccubbin, A.E., 1997. Lipid peroxidation and DNA damage. Nutrition 3, 920-921. https://doi.org/10.1016/S0899-9007(97)00260-8

7. Bradford, M.M., 1976. A rapid sensitivemethod for the quantification of microgram quantities of protein utilizing the principle of protein-dye binding. Analytical Biochemistry 72, 248-254. https://doi.org/10.1016/0003-2697(76)90527-3

8. Cáceres, T., He, W.X., Naidu, R., Megharaj, M., 2007. Toxicity of chlorpyrifos and TCP alone and in combination to Daphnia carinata: the influence of microbial degradation in natural water. Water Research 41(19), 4497-4503. https://doi.org/10.1016/j.watres.2007.06.025

9. Costa, E., Gambardella, C., Piazza, V., Greco, G., Lavorano, S., Beltrandi, M., Bongiovanni, E., Gnone, G., Faimali, M., Garaventa, F., 2015. Effect of neurotoxic compounds on ephyrae of Aurelia aurita jellyfish. Hydrobiologia 759(1), 75-84. https://doi.org/10.1007/s10750-015-2284-3

10. Deng, Y.F., Zhang, Y., Lu, Y.F., Zhao, Y.P., Ren, H.Q., 2016. Hepatotoxicity and nephrotoxicity induced by the chlorpyrifos and chlorpyrifos-methyl metabolite, 3,5,6-trichloro-2-pyridinol, in orally exposed mice. Science of The Total Environment 544, 507-514. https://doi.org/10.1016/j.scitotenv.2015.11.162

11. Dutta, M., Sardar, D., Pal, R. and Kole, R.K., 2010. Effect of chlorpyrifos on microbial biomass and activities in tropical clay loam soil. Environmental Monitoring and Assessment 160(1-4), 385-391. https://doi.org/10.1007/s10661-008-0702-y

12. Echeverri-Jaramillo, G., Jaramillo-Colorado, B., Sabater-Marco, C. and Castillo-Lopez, M. Á., 2020. Acute toxicity of chlorpyrifos and its metabolite 3,5,6-trichloro-2-pyridinol alone and in combination 
using a battery of bioassays. Environmental Science and Pollution Research 27(26), 32770-32778. https://doi.org/10.1007/s11356-020-09392-x

13. Garcia-Gomez, C., Babin, M., Garcia, S., Almendros, P., Perez, R.A., Fernandez, M.D., 2019. Joint effects of zinc oxide nanoparticles and chlorpyrifos on the reproduction and cellular stress responses of the earthworm Eisenia andrei. Science of The Total Environment 688, 199-207. https://doi.org/10.1016/j.scitotenv.2019.06.083

14. Gebremariam, S.Y., Beutel, M.W., Flury, M., Harsh, J.B., Yonge, D.R., 2012. Nonsingular adsorption/desorption of chlorpyrifos in soils and sediments: experimental results and modeling. Environmental Science \& Technology 46(2), 869-875. https://doi.org/10.1021/es203341b

15. Guo, Y., Weck, J., Sundaram, R., Goldstone, A.E., Louis, G.B., Kannan, K., 2014. Urinary concentrations of phthalates in couples planning pregnancy and its association with 8-hydroxy-2'-deoxyguanosine, a biomarker of oxidative stress: longitudinal investigation of fertility and the environment study. Environmental Science \& Technology 48(16), 9804-9811. https://doi.org/10.1021/es5024898

16. John, E.M., Shaike, J.M., 2015. Chlorpyrifos: pollution and remediation. Environmental Chemistry Letters 13(3), 269-291. https://doi.org/10.1007/s10311-015-0513-7

17. Kharabsheh, H.A., Han, S.B., Allen, S., Chao, S.L., 2017. Metabolism of chlorpyrifos by Pseudomonas aeruginosa increases toxicity in adult zebrafish (Danio rerio). International Biodeterioration \& Biodegradation 121, 114-121. https://doi.org/10.1016/j.ibiod.2017.03.024

18. Li, J.W., Fang, B., Ren, F.Z., Xing, H.Z., Zhao, G.P., Yin, X.F., Pang, G.F., Li, Y.X., 2020. TCP structure intensified the chlorpyrifos-induced decrease in testosterone synthesis via LH-LHR-PKA-CREB-Star pathway. Science of The Total Environment 726, 138496.

https://doi.org/10.1016/j.scitotenv.2020.138496

19. Li, M., Wang, S., Lang, Z., Xu, G.H., Yu, Y., 2019. Combination of chemical and toxicological methods to assess bioavailability of Tolclofos-methyl by earthworms. Chemosphere 233, 183-189. https://doi.org/10.1016/j.chemosphere.2019.05.215

20. Liu, T., Liu, Y.L., Fang, K., Zhang, X.L., Wang, X.G., 2020a. Transcriptome, bioaccumulation and toxicity analyses of earthworms (Eisenia fetida) affected by trifloxystrobin and trifloxystrobin acid. Environmental Pollution 265, 115100. https://doi.org/10.1016/j.envpol.2020.115100

21. Liu, T., Zhang, X.L., Wang, X.G., Chen, D., Li, Y.Q., Wang, F.L., 2018. Comparative toxicity and bioaccumulation of two dinotefuran metabolites, UF and DN, in earthworms (Eisenia fetida). Environmental Pollution 234, 988-996. https://doi.org/10.1016/j.envpol.2017.12.007

22. Liu, Y.M., Li, L., Zheng, L., Fu, P., Wang, Y., Nguyen, H., Shen, X.S., Sui, Y.M., 2020b. Antioxidant responses of triangle sail mussel Hyriopsis cumingii exposed to harmful algae Microcystis aeruginosa and high $\mathrm{pH}$. Chemosphere 243, 125241. https://doi.org/10.1016/j.chemosphere.2019.125241

23. OECD, 2016. Test No. 222: Earthworm Reproduction Test (Eisenia fetida/Eisenia andrei), OECD Guidelines for the Testing of Chemicals, Section 2, OECD Publishing, Paris. 
24. Ojha, A., Yaduvanshi, S.K., Pant, S.C., Lomash, V., Srivastava, N., 2013. Evaluation of DNA damage and cytotoxicity induced by three commonly used organophosphate pesticides individually and in mixture, in rat tissues. Environmental Toxicology 28(10), 543-552. https://doi.org/10.1002/tox.20748

25. Orts, A., Cabrera, S., Gómez, I., Parrado, J., Rodriguez-Morgado, B., Tejada, M., 2017. Use of okara in the bioremediation of chlorpyrifos in soil: Effects on soil biochemical properties. Applied Soil Ecology 121, 172-176. https://doi.org/10.1016/j.apsoil.2017.09.042

26. Samanta, P., Im, H., Na, J., Jung, J., 2018. Ecological risk assessment of a contaminated stream using multi-level integrated biomarker response in Carassius auratus. Environmental Pollution 233, 429-438. https://doi.org/10.1016/j.envpol.2017.10.061

27. Sanchez-Hernandez, J.C., Ríos, J.M., Attademo, A.M., Malcevschi, A., Andrade Cares, X., 2019. Assessing biochar impact on earthworms: Implications for soil quality promotion. Journal of Hazardous Materials 366, 582-591. https://doi.org/10.1016/j.jhazmat.2018.12.032

28. Sanchez, W., Burgeot, T., Porcher, J.M., 2013. A novel "Integrated Biomarker Response" calculation based on reference deviation concept. Environmental Science and Pollution Research 20(5), 27212725. https://doi.org/10.1007/s11356-012-1359-1

29. Sandal, S., Yilmaz, B., 2011. Genotoxic effects of chlorpyrifos, cypermethrin, endosulfan and 2,4-D on human peripheral lymphocytes cultured from smokers and nonsmokers. Environmental Toxicology 26(5), 433-442. https://doi.org/10.1002/tox.20569

30. Shao, Y.T., Hou, K.X., Du, Z.K., Li, B., Wang, J., Juhasz, A., Wang, J.H., Zhu, L.S., 2019. Evaluation of the toxicity of 1-butyl-3-methyl imidazolium tetrafluoroborate using earthworms (Eisenia fetida) in two soils. Science of The Total Environment 686, 946-958.

https://doi.org/10.1016/j.scitotenv.2019.06.010

31. Song P.P., Gao J.P., Li X.X., Zhang C., Zhu L.S., Wang J.H., Wang J., Phthalate induced oxidative stress and DNA damage in earthworms (Eisenia fetida). Environment International 129, 10-17. https://doi.org/10.1016/j.envint.2019.04.074

32. Stepnowski, P., Wojciech M., Nichthauser, J., 2007. Adsorption of alkyl imidazolium and alkyl pyridinium ionic liquids onto natural soils. Environmental Science \& Technology 41 (2), 511-516. https://doi.org/10.1021/es062014w

33. Suvarchala, G., Philip, G.H., 2016. Toxicity of 3,5,6-trichloro-2-pyridinol tested at multiple stages of zebrafish (Danio rerio) development. Environmental Science and Pollution Research 23(15), 1551515523. https://doi.org/10.1007/s11356-016-6684-3

34. Wang, C., Lu, G.H., Wang, P.F., Wu, H., Qi, P.D., Liang, Y., 2011. Assessment of environmental pollution of Taihu Lake by combining active biomonitoring and integrated biomarker response. Environmental Science \& Technology 45(8), 3746-3752. https://doi.org/10.1021/es1037047

35. Wang, G.Y., Wang, J., Zhu, L.S., Wang, J.H., Li, H.Z., Zhang, Y.Z., Liu, W.J., Gao, J.P., 2018. Oxidative Damage and Genetic Toxicity Induced by DBP in Earthworms (Eisenia fetida). Archives of Environmental Contamination and Toxicology 74(4), 527-538. https://doi.org/10.1007/s00244-017$0451-4$ 
36. Wang, J., Wang, J.H., Zhu, L.S., Xie, H., Shao, B., Hou, X.X., 2014. The enzyme toxicity and genotoxicity of chlorpyrifos and its toxic metabolite TCP to zebrafish Danio rerio. Ecotoxicology 23(10), 1858-1869. https://doi.org/10.1007/s10646-014-1321-8

37. Wang, J.H., Zhu, L.S., Liu, W., Wang, J., Xie, H., 2012. Biochemical responses of earthworm (Eisenia foetida) to the pesticides chlorpyrifos and fenvalerate. Toxicology Mechanisms and Methods 22(3), 236-241. https://doi.org/10.3109/15376516.2011.640718

38. Wang, S.H., Zhang, C., Lv, Z.W., Huang, H.M., Cao, X.T., Song, Z.F., Shao, M.Z., 2019. Degradation of 3,5,6-trichloro-2-pyridinol by a microbial consortium in dryland soil with anaerobic incubation. Biodegradation 30(2-3), 161-171. https://doi.org/10.1007/s10532-019-09873-y

39. Wen Y., Zhou L.L., Li D., Lai Q., Shi H.Y., Wang M.H., 2020. Ecotoxicological effects of the pyrethroid insecticide tefluthrin to the earthworm Eisenia fetida: A chiral view. Environmental Research 190, 109991. https://doi.org/10.1016/j.envres.2020.109991

40. Xu Y.Q., Li B., Hou K.X., Du Z.K., Allen C.S., Zhu L.S., Li W.X., Zhu L., Wang J.H. Wang J. 2021. Ecotoxicity evaluation of azoxystrobin on Eisenia fetida in different soils. Environmental Research 194, 110705. https://doi.org/10.1016/j.envres.2020.110705

41. Yu, X.F, Zhu, H., Yan, B.X., Xu, Y.Y., Banuelos, G., Shutes, B., Wen, H.Y., Cheng, R., 2019. Removal of chlorpyrifos and its hydrolytic metabolite 3,5,6-trichloro-2-pyridinol in constructed wetland mesocosms under soda saline-alkaline conditions: Effectiveness and influencing factors. Journal of Hazardous Materials 373, 67-74. https://doi.org/10.1016/j.jhazmat.2019.03.052

42. Žabar, R., Sarakha, M., Lebedev, A.T., Polyakova, O.V., Trebse, P., 2016. Photochemical fate and photocatalysis of 3,5,6-trichloro-2-pyridinol, degradation product of chlorpyrifos. Chemosphere 144, 615-620. https://doi.org/10.1016/j.chemosphere.2015.09.030

43. Zhang, C., Wang, S.H., Lv, Z.W., Zhang, Y., Cao, X.T., Song, Z.F., Shao, M.Z., 2019. $\mathrm{NanoFe}_{3} \mathrm{O}_{4}$ accelerates anoxic biodegradation of 3, 5, 6-trichloro-2-pyridinol. Chemosphere 235, 185-193. https://doi.org/10.1016/j.chemosphere.2019.06.114

44. Zhang, C., Zhu, L.S., Wang, J., Wang, J.H., Du, Z., Li, B., Zhou, T.T., Cheng, C., Wang, Z.B., 2018. Evaluating subchronic toxicity of fluoxastrobin using earthworms (Eisenia fetida). Science of The Total Environment 642, 567-573. https://doi.org/10.1016/j.scitotenv.2018.06.091

45. Zhang, L.J., Ji, F.N., Li, M., Cui, Y.B., Wu, B., 2014. Short-term effects of Dechlorane Plus on the earthworm Eisenia fetida determined by a systems biology approach. Journal of Hazardous Materials 273, 239-246. https://doi.org/10.1016/j.jhazmat.2014.03.018

46. Zhu, L.S., Dong, X.L., Xie, H., Wang, J., Wang, J.H., Su, J., Yu, C.W., 2011. DNA damage and effects on glutathione-S-transferase activity induced by atrazine exposure in zebrafish (Danio rerio). Environmental Toxicology 26(5), 480-488. https://doi.org/10.1002/tox.20575

47. Zhu, L., Li, B., Wu, R.L., Li, W.X., Wang, J., Wang, J.H., Du, Z.K., Juhasz, A., Zhu, L.S., 2020. Acute toxicity, oxidative stress and DNA damage of chlorpyrifos to earthworms (Eisenia fetida): The difference between artificial and natural soils. Chemosphere 255, 126982. https://doi.org/10.1016/j.chemosphere.2020.126982 
Figures

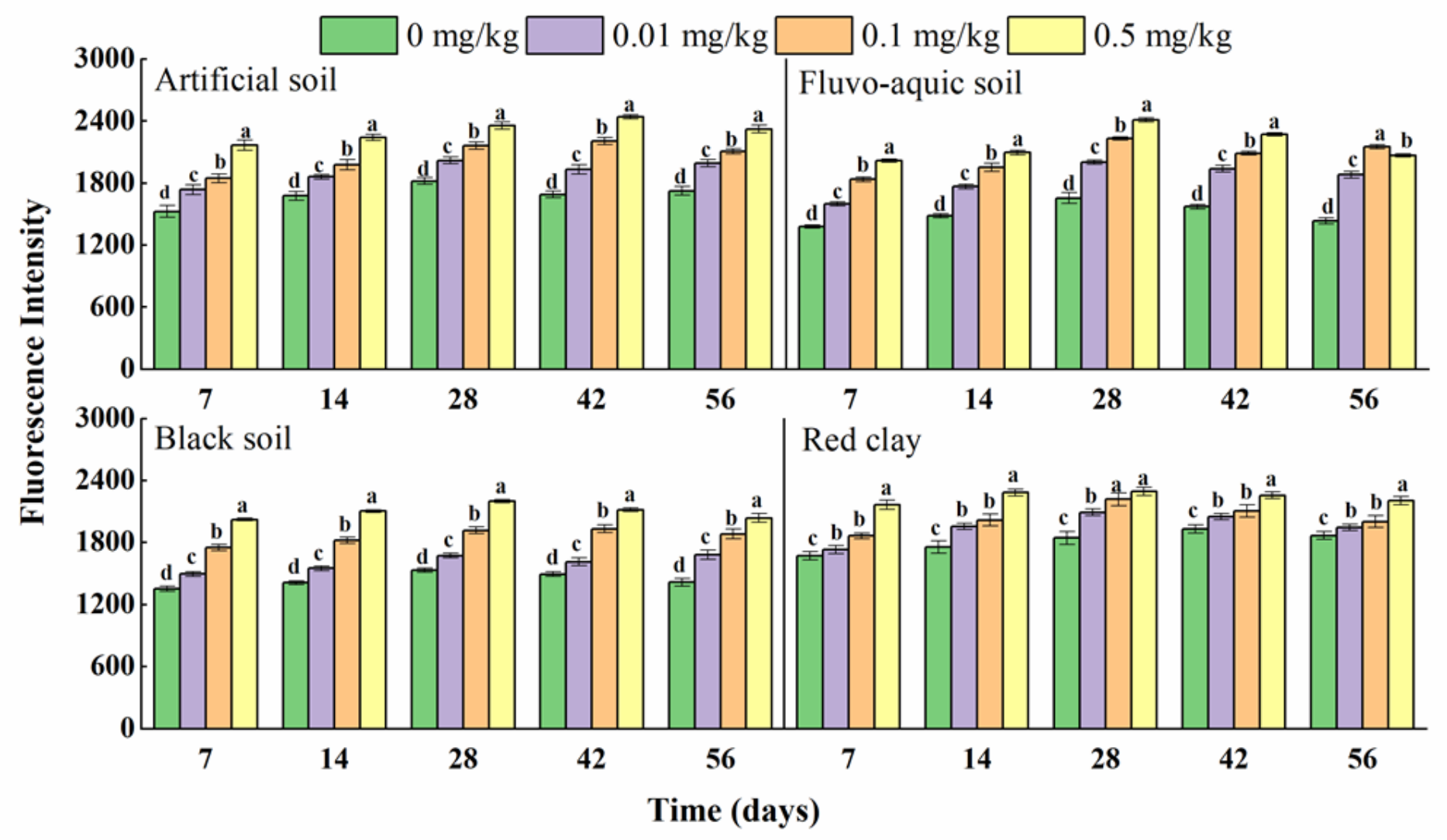

Figure 1

TCP concentration effect on earthworm's ROS contents in different soils. Different letters above columns represent a significant difference between groups in the same exposure time $(p<0.05)$. 


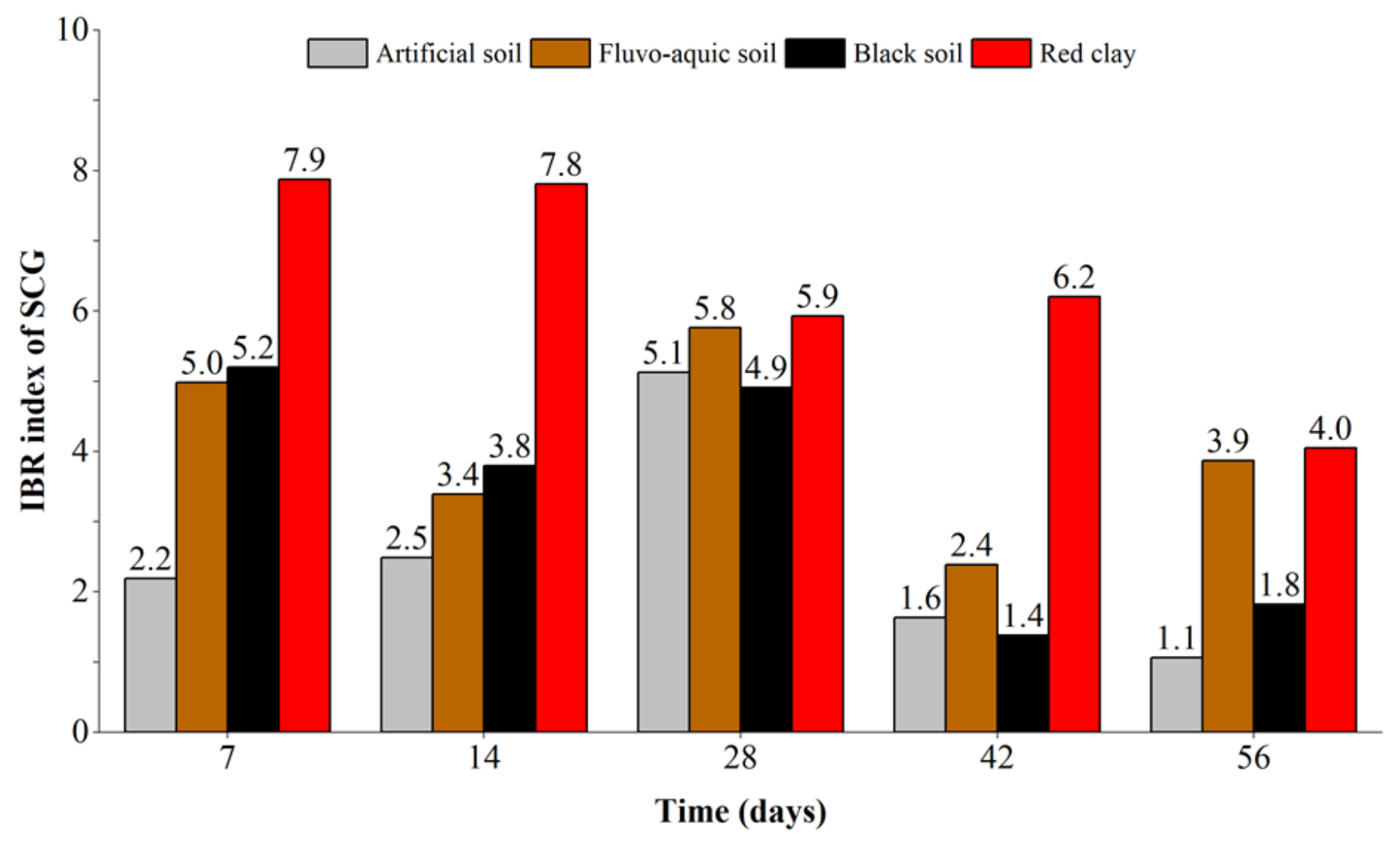

Figure 2

Integrated biomarker response (IBR) index calculated by SOD, CAT and GST (IBR index of SCG) of mid concentration. 


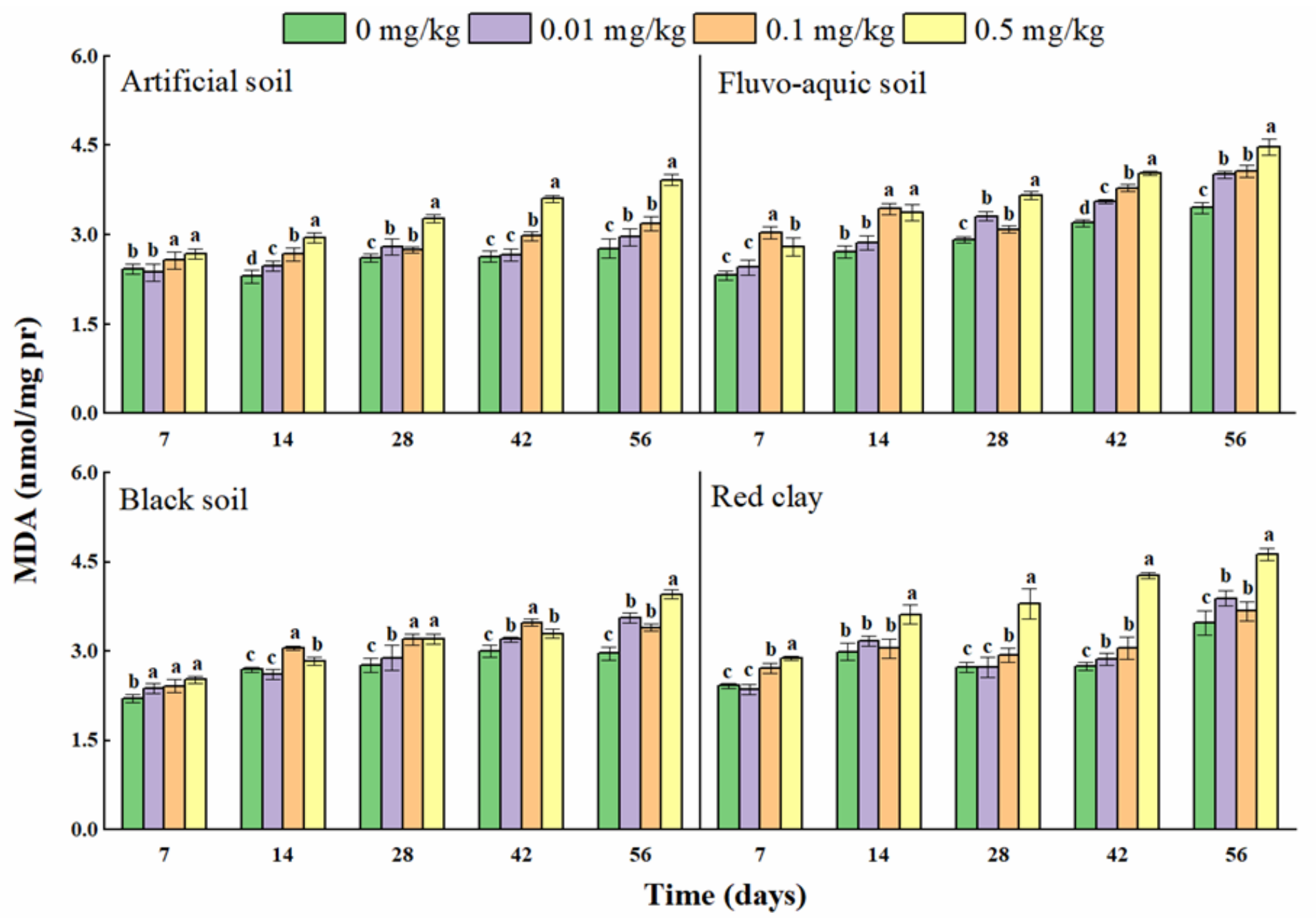

Figure 3

Effect of TCP concentration on MDA content in Eisenia fetida in different soils. Different letters above columns represent a significant difference between concentrations in the same exposure time $(p<0.05)$. 


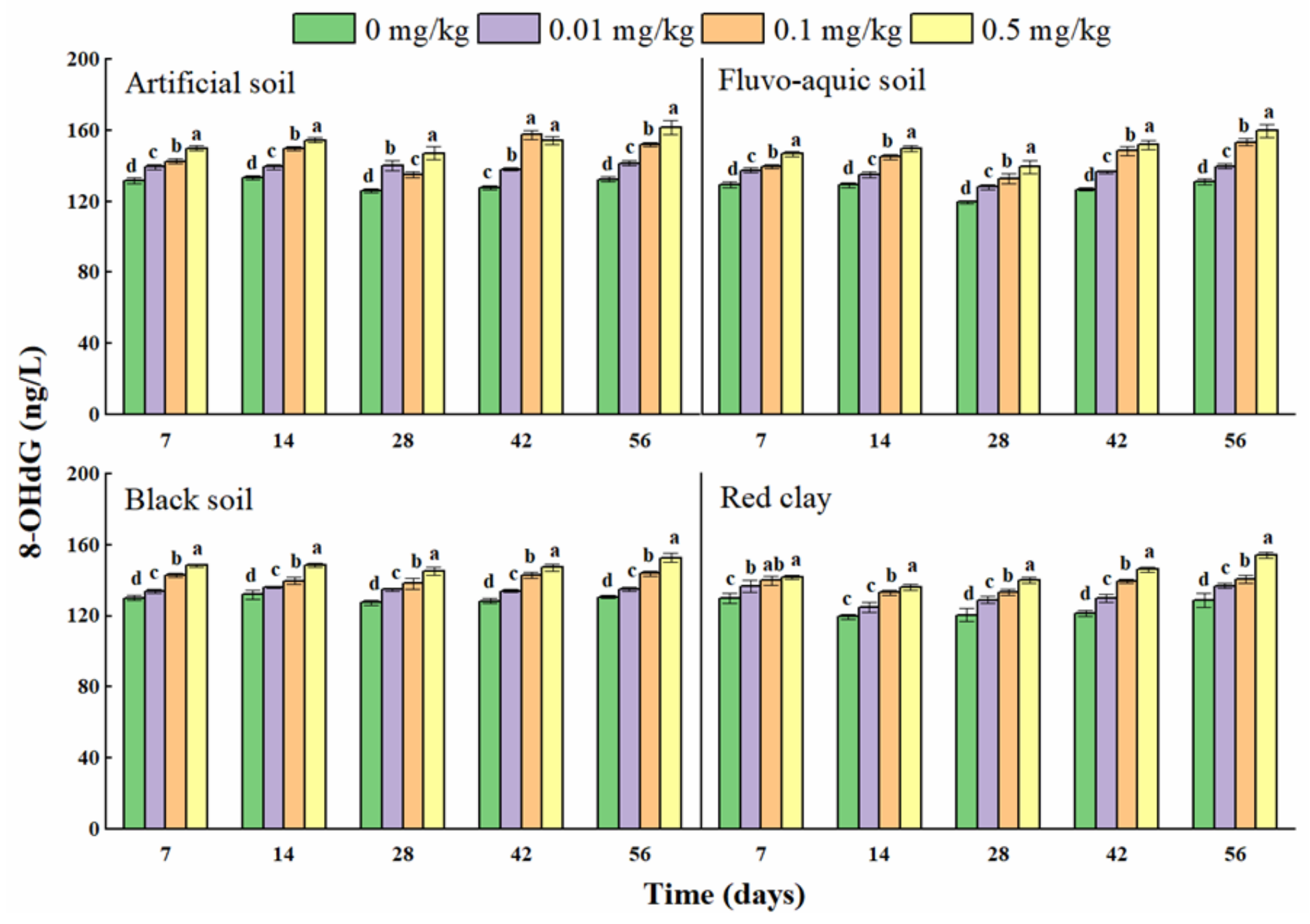

Figure 4

Effect of TCP on 8-OHdG concentration in earthworms. Different letters above columns represent a significant difference between concentrations in the same exposure time $(p<0.05)$ 


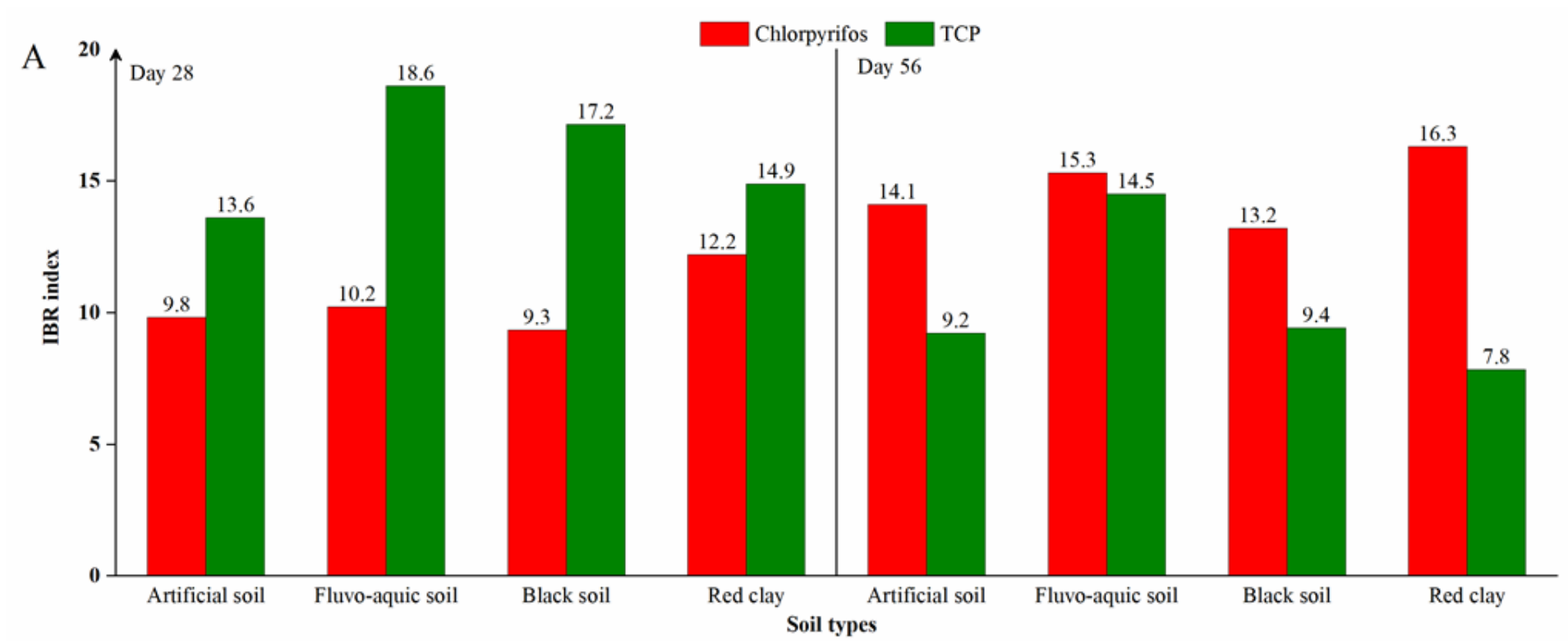

B

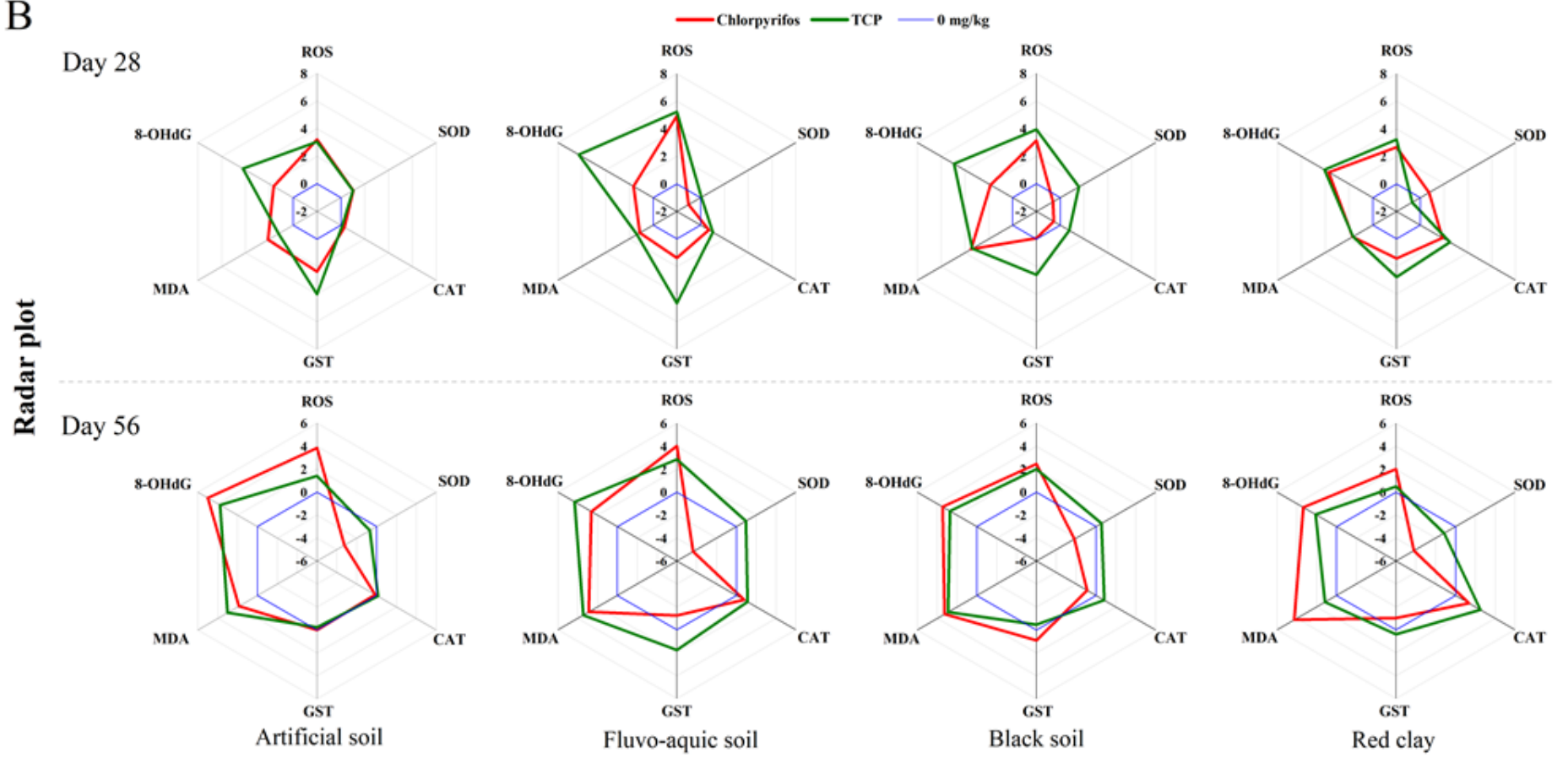

Figure 5

IBR index (A) and radar plot (B) that $0.1 \mathrm{mg} / \mathrm{kg}$ chlorpyrifos (Zhu et, al. 2020) and TCP treated after 28 and 56 days. The blue line in the radar plot means the solvent control group $(0 \mathrm{mg} / \mathrm{kg})$ values for Eisenia fetida.

\section{Supplementary Files}

This is a list of supplementary files associated with this preprint. Click to download. 
- Supplementarymaterial.doc

Page 19/19 